\title{
Mg isotopic compositions of stony spherules from deep-sea sediments
}

\author{
KeiJi Misawa ${ }^{1 *}$, KaZuo Yamakoshi ${ }^{1}$ and Noboru NaKamura ${ }^{2}$ \\ Institute for Cosmic Ray Research, University of Tokyo, \\ Tanashi, Tokyo $188^{1}$, \\ and Department of Earth Sciences, Faculty of Science, Kobe University, \\ Nada, Kobe $657^{2}$, Japan
}

(Received August 12, 1991; Accepted February 15, 1992)

\begin{abstract}
The isotopic compositions of $\mathrm{Mg}$ in 5 individual stony spherules from deep-sea sediments have been measured. The spherules are composed of olivine, glass, and magnetite, and considered to be of extraterrestrial origin. No significant mass fractionation of up to 2 per mil per amu was recognized. One sample showed a small but significant non-linear ${ }^{26} \mathrm{Mg}$ isotopic effect $\left(\delta^{26} \mathrm{Mg}=+1.2\right.$ per mil) similar to that reported in interplanetary dust particles (IDPs). Based on Mg isotopic compositions of the spherules, we suggest that either vaporization mass loss of parent meteoroids of stony spherules was not so large, usually less than $\sim 20 \%$, or ablative mass loss occurred effectively during entry into the Earth's atmosphere, and that physicochemical fractionations took place in parent meteoroids could be related to those of primitive IDPs. The processes responsible for the non-linear effect of ${ }^{26} \mathrm{Mg}$, however, remain undefined.
\end{abstract}

\section{INTRODUCTION}

The cosmic spherules collected from the ocean floor are important sources of extraterrestrial material (e.g., Brownlee, 1981, 1985 and references therein). As is the case with meteoritic chondrules (e.g., Misawa and Nakamura, 1988), detailed REE patterns may constrain not only the nature of the parent meteoroids but also the melting conditions of these material. In addition, the study of $\mathrm{O}, \mathrm{Mg}$, and $\mathrm{Si}$ isotopic mass fractionations can help us to better understand melting conditions of parent bodies that enter the Earth's atmosphere. Because of the limited sizes of individual spherules (typically less than $200 \mu \mathrm{g}$ ), the fine structures of trace element abundances, especially REE patterns, and the isotopic compositions of $\mathrm{O}, \mathrm{Mg}$, and $\mathrm{Si}$ are not well understood except in only a few cases (e.g.,
Nagasawa et al., 1979; Clayton et al., 1986; Davis et al., 1991).

In order to further clarify the chemical and isotopic characteristics of these spherules, we have undertaken isotope dilution analysis of the $\mathrm{REE}$ and isotopic measurements of $\mathrm{Mg}$ together with instrumental neutron activation analysis (INAA) of major and trace elements, and part of this study will appear elsewhere (Misawa et al., 1992). We present here the $\mathrm{Mg}$ isotopic data for 5 individual stony spherules and discuss the implications of the data on melting and vaporization processes during entry into the Earth's atmosphere as well as the physicochemical fractionations that took place on the parent meteoroids. Preliminary data from our study were reported by Misawa and Yamakoshi (1990).

*Present address: U.S. Geological Survey, Branch of Isotope Geology, M.S. 963, Box 25046, Federal Center, Denver, CO 80225, U.S.A. 


\section{EXPERIMENTAL}

\section{Samples}

More than 50 stony spherules were separated magnetically from pelagic clay dredged by the $R /$ V Hakurei-Maru near the Hawaiian islands at a depth of $\sim 4500 \mathrm{~m}$. The spherules were handpicked under a binocular microscope. They were weighed using a Cahn-29 automatic electrobalance, and 5 spherules larger than $10 \mu \mathrm{g}$ were selected for $\mathrm{Mg}$ isotopic analysis. After ultrasonic cleaning in distilled water and distilled acetone, each spherule was broken into two parts using an agate mortar. One part was mounted in epoxy resin and polished with diamond paste for SEM observation. The other part was used for the $\mathrm{Mg}$ isotope measurement. The spherules were examined by a JEOL JMS740 electron microprobe. Constituent phases were identified using a Kevex Delta-3000 energy dispersive spectrometer system on the electron microprobe. Textures were observed by backscattered electron images. All spherules analyzed in this study show barred-dendritic textures (Fig. 1) typically observed in cosmic spherules, and are considered to be of extraterrestrial origin.

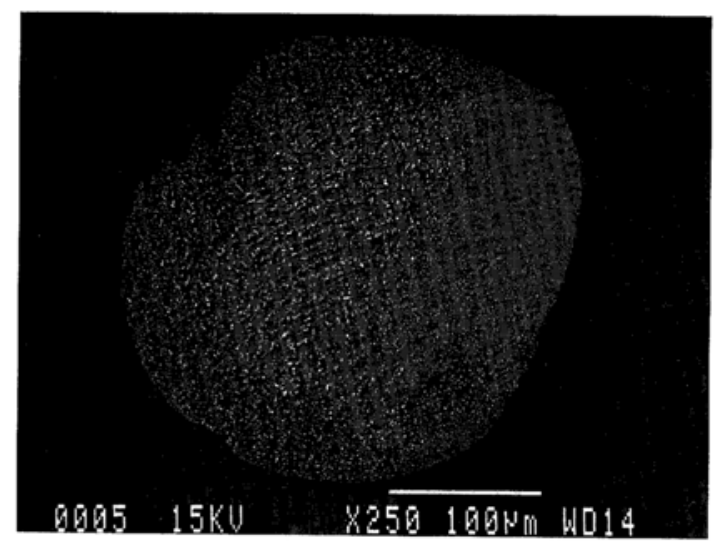

Fig. 1. Back-scattered electron image of spherule HWI-5 which is composed of barred-dendritic olivine (medium gray), glass (dark), and magnetite (bright). The texture strongly suggests that the spherule melted totally. Outer surfaces of the spherule have lightly experienced etching by seawater (the darkest areas).

\section{Chemistry}

Reagents used during chemistry were purified by the following methods. Acetone was distilled in a Pyrex glass still. $\mathrm{H}_{2} \mathrm{O}$ was first distilled in a stainless steel boiling still, then distilled twice in quartz boiling stills, and finally distilled in a quartz sub-boiling still. $\mathrm{HCl}$ was obtained by bubbling high purity $\mathrm{HCl}$ gas into distilled water. $\mathrm{HF}$ and $\mathrm{HClO}_{4}$ were taken from commercial products (sub-boiling purified reagents; NBS Analytical Chemistry Division).

The samples were dissolved with $2-3 \mu \mathrm{l}$ of a $\mathrm{HF}-\mathrm{HClO}_{4}$ mixture in a sealed teflon bomb. After evaporating to dryness and redissolved in $1 N \mathrm{HCl}$, they were passed twice through a 300 $\mu \mathrm{l}$-volume quartz column packed with Dowex AG $50 \mathrm{~W}$ X-12 (200-400 mesh) cation exchange resin. $\mathrm{Mg}$ was eluted with $1 \mathrm{~N} \mathrm{HCl}$. For small samples, HWI-3 and -4 , column chemistry was performed once. The total procedural Mg blank was measured by isotope dilution. Using the normal chemistry (two column separations), the final $\mathrm{Mg}$ fraction was collected and then spiked with a ${ }^{25} \mathrm{Mg}$ tracer. The total collected fraction (both passes) yielded a blank less than $0.5 \mathrm{ng}$. We usually loaded $1 / 4$ to $1 / 10$ of the collected $\mathrm{Mg}$ fraction on the filament per run, and the contribution of the loading blank to the total blank was considered to be small. Since we ran $\mu \mathrm{g}$ of $\mathrm{Mg}$ during this work, the data are not corrected for blank.

\section{Mass spectrometry}

The isotopic composition of $\mathrm{Mg}$ was determined using a VG-354 mass spectrometer with a single Faraday collector. The thermal ionization was carried out by the single Re V-shaped filament mode (Lee et al., 1977 a). Samples (200$500 \mathrm{ng}$ of $\mathrm{Mg}$ ) were loaded on an out-gassed $\left(<1 \times 10^{-7}\right.$ Torr, $4.5 \mathrm{~A}$ for $2 \mathrm{hrs}$ ) filament with 2 $\mu \mathrm{l}$ of silica gel and $5 \mu \mathrm{l}$ of $3 \mathrm{~N} \mathrm{H}_{3} \mathrm{PO}_{4}$ as an activator (Schramm et al., 1970), and baked at $\sim 1000^{\circ} \mathrm{C}$ for $10 \mathrm{hrs}$ to remove $\mathrm{Na}$. The filament temperature was increased gradually to $\sim 1500^{\circ} \mathrm{C}$. A single charged ${ }^{24} \mathrm{Mg}$ signal larger than $10^{-11} \mathrm{~A}$ was sustained over a period of $5 \mathrm{hrs}$ with $200 \mathrm{ng}$ of $\mathrm{Mg}$. During measuring, $\mathrm{Na}, \mathrm{Mg}$, 
and $\mathrm{Al}$ mass regions were monitored. Neither hydrocarbon nor scattering peaks from $\mathrm{Na}$ and $\mathrm{Al}$ were recognized. Isotopic measurements were carried out with a general peak jumping mode in the cyclic order ${ }^{24} \mathrm{Mg}-{ }^{25} \mathrm{Mg}-{ }^{26} \mathrm{Mg}-{ }^{24} \mathrm{Mg}$. Fifteen sequential cycles were grouped in one set, and the mean raw ratios and the average of fractionation corrected ratios were calculated. The only selection criterion for these sets was that the standard deviation of the mean must be less than 1 per mil for ${ }^{25} \mathrm{Mg} /{ }^{24} \mathrm{Mg}$ and 2 per mil for
${ }^{26} \mathrm{Mg} /{ }^{24} \mathrm{Mg}$. Usually over 20 sets were obtained during one analysis. For normalization we used ${ }^{25} \mathrm{Mg} /{ }^{24} \mathrm{Mg}=0.12663$ (Catanzaro et al., 1966), and mass fractionation was corrected using a power law.

\section{Results AND Discussion}

\section{Normals}

Standards of normal $\mathrm{Mg}$ composition, reagent $\mathrm{MgO}$, separated $\mathrm{Mg}$ from KLB-1 lher-

Table 1. Results of Mg analyses

\begin{tabular}{|c|c|c|c|}
\hline $\begin{array}{l}\text { Sample } \\
\text { (weight) }\end{array}$ & $\begin{array}{c}\text { meas } \\
{ }^{25} \mathrm{Mg} /{ }^{24} \mathrm{Mg} \\
\pm 2 \sigma\end{array}$ & $\begin{array}{l}{ }^{26} \mathrm{Mg} /{ }^{24} \mathrm{Mg} \\
\quad \pm 2 \sigma^{\sharp 1}\end{array}$ & $\begin{array}{c}\text { frac. corrected } \\
{ }^{26} \mathrm{Mg} /{ }^{24} \mathrm{Mg} \\
\pm 2 \sigma_{\text {mean }}^{\#}\end{array}$ \\
\hline \multirow[t]{14}{*}{$\mathrm{MgO}$} & $0.124636 \pm 92$ & $0.135452 \pm 290$ & $0.139869 \pm 56$ \\
\hline & $0.124621 \pm 98$ & $0.135416 \pm 268$ & $0.139878 \pm 66$ \\
\hline & $0.124568 \pm 134$ & $0.135286 \pm 190$ & $0.139749 \pm 196$ \\
\hline & $0.124505 \pm 138$ & $0.135126 \pm 360$ & $0.139804 \pm 74$ \\
\hline & $0.124603 \pm 112$ & $0.135328 \pm 108$ & $0.139797 \pm 137$ \\
\hline & $0.124550 \pm 186$ & $0.135245 \pm 476$ & $0.139760 \pm 54$ \\
\hline & $0.124539 \pm 278$ & $0.135202 \pm 648$ & $0.139800 \pm 52$ \\
\hline & $0.124574 \pm 92$ & $0.135279 \pm 292$ & $0.139858 \pm 68$ \\
\hline & $0.124618 \pm 100$ & $0.135417 \pm 146$ & $0.139810 \pm 54$ \\
\hline & $0.124609 \pm 94$ & $0.135393 \pm 206$ & $0.139815 \pm 36$ \\
\hline & $0.124646 \pm 140$ & $0.135521 \pm 226$ & $0.139873 \pm 84$ \\
\hline & $0.124654 \pm 118$ & $0.135510 \pm 310$ & $0.139845 \pm 40$ \\
\hline & $0.124567 \pm 144$ & $0.135367 \pm 330$ & $0.139881 \pm 40$ \\
\hline & $0.124710 \pm 128$ & $0.135571 \pm 206$ & $0.139780 \pm 42$ \\
\hline \multirow[t]{3}{*}{ KLB1-OL } & $0.124745 \pm 84$ & $0.135655 \pm 124$ & $0.139753 \pm 74$ \\
\hline & $0.124818 \pm 104$ & $0.135812 \pm 292$ & $0.139743 \pm 52$ \\
\hline & $0.124764 \pm 180$ & $0.135665 \pm 532$ & $0.139779 \pm 52$ \\
\hline \multirow[t]{2}{*}{ Peace River } & $0.124630 \pm 216$ & $0.135431 \pm 336$ & $0.139833 \pm 84$ \\
\hline & $0.124783 \pm 88$ & $0.135734 \pm 284$ & $0.139812 \pm 82$ \\
\hline Av. of Normals & $0.124639 \pm 1719$ & $0.135443 \pm 360$ & $0.139813 \pm 21 \ddagger$ \\
\hline HWI-1 & $0.124808 \pm 152$ & $0.135817 \pm 390$ & $0.139850 \pm 50$ \\
\hline \multicolumn{4}{|l|}{$(81.8 \mu \mathrm{g})$} \\
\hline HWI-2 & $0.124761 \pm 76$ & $0.135828 \pm 158$ & $0.139956 \pm 52$ \\
\hline$(35.2 \mu \mathrm{g})$ & $0.124808 \pm 134$ & $0.135934 \pm 210$ & $0.139991 \pm 44$ \\
\hline HWI-3 & $0.124739 \pm 140$ & $0.135778 \pm 246$ & $0.139877 \pm 76$ \\
\hline \multicolumn{4}{|l|}{$\left(8.5 \mu \mathrm{g}^{*}\right)$} \\
\hline HWI-4. & $0.124862 \pm 126$ & $0.135947 \pm 236$ & $0.139789 \pm 64$ \\
\hline$(17.3 \mu \mathrm{g})$ & $0.124905 \pm 56$ & $0.136026 \pm 122$ & $0.139804 \pm 56$ \\
\hline HWI-5 & $0.124945 \pm 120$ & $0.136196 \pm 226$ & $0.139902 \pm 52$ \\
\hline \multicolumn{4}{|l|}{$(58.8 \mu \mathrm{g})$} \\
\hline
\end{tabular}

\#Errors correspond to the last digits shown and are $2 \sigma$ for raw ratios or $2 \sigma$ mean for fractionation corrected ${ }^{26} \mathrm{Mg} /{ }^{24} \mathrm{Mg}$ ratios.

\$Corrected for fractionation according to $\left({ }^{26} \mathrm{Mg} /{ }^{24} \mathrm{Mg}\right)_{\mathrm{c}}=\left({ }^{26} \mathrm{Mg} /{ }^{24} \mathrm{Mg}\right)_{\text {meas }} / \alpha^{2}$, where 'meas' is the measured ratio during the set, $\alpha=\left({ }^{25} \mathrm{Mg} /{ }^{24} \mathrm{Mg}\right)_{\text {meas }} /\left({ }^{25} \mathrm{Mg} /{ }^{24} \mathrm{Mg}\right)_{\text {o }}$, and $\left({ }^{25} \mathrm{Mg} /{ }^{24} \mathrm{Mg}\right)_{c}=0.12663$ reported by Catanzaro et al. (1966). After corrected for mass fractionation, the mean ratios were calculated.

${ }^{*}$ Fragment of spherule. Original mass was $>10 \mu \mathrm{g}$.

Average of 19 runs. Errors are $2 \sigma$.

$\ddagger$ Average of 19 runs. Errors are $2 \sigma$ mean. 

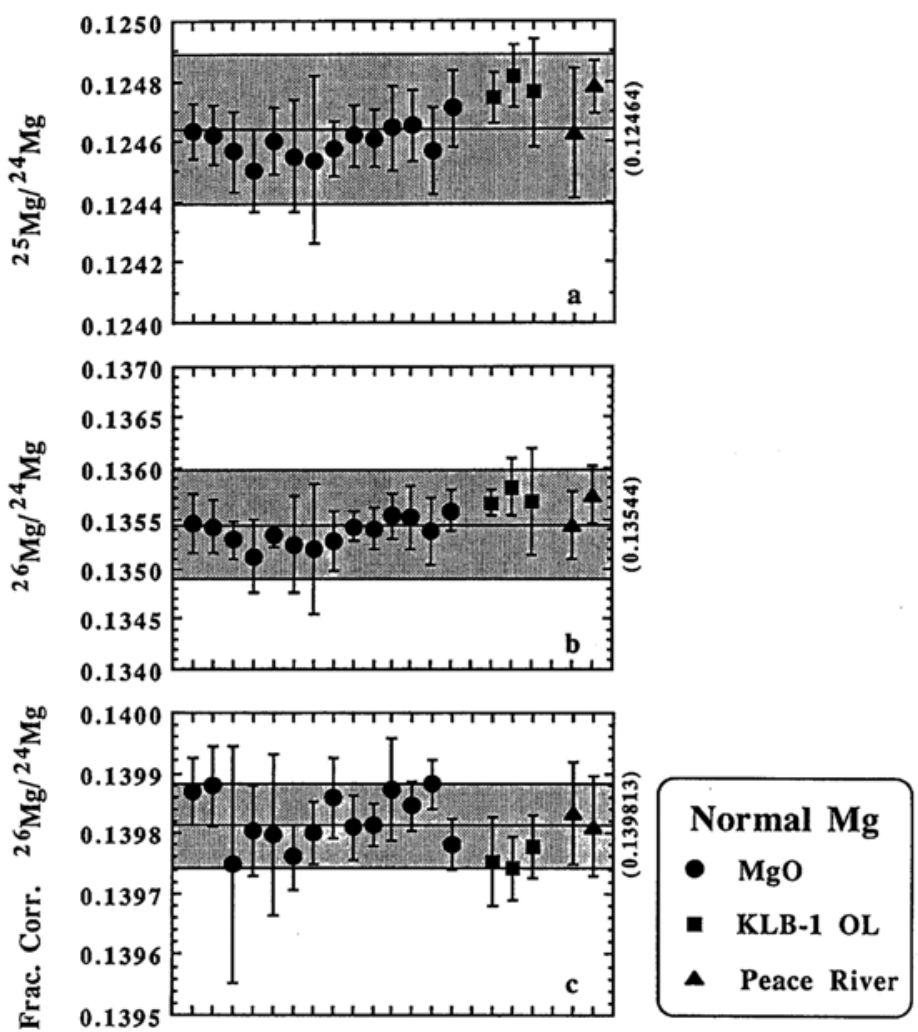

Fig. 2. Mass spectrometric measurements of normal $\mathrm{Mg}$ (reagent $\mathrm{MgO}, \mathrm{KLB}-1$ lherzolite olivine, and the Peace River meteorite). Shaded areas for (a), (b), and (c) are \pm 2 per mil, \pm 4 per mil, and \pm 0.5 per mil error bands, respectively. (a) Uncorrected ${ }^{25} \mathrm{Mg} /{ }^{24} \mathrm{Mg}$ ratios. The grand mean value of uncorrected ${ }^{25} \mathrm{Mg} /{ }^{24} \mathrm{Mg}$ is 0.12464 . (b) Uncorrected ${ }^{26} \mathrm{Mg} /{ }^{24} \mathrm{Mg}$ ratios. The grand mean value of uncorrected ${ }^{26} \mathrm{Mg} /{ }^{24} \mathrm{Mg}$ is 0.13544 . (c) Fractionation corrected ${ }^{26} \mathrm{Mg} /{ }^{24} \mathrm{Mg}$ ratios. The grand mean value of fractionation corrected ${ }^{26} \mathrm{Mg} /{ }^{24} \mathrm{Mg}$ is 0.139813. Mass fractionation was corrected according to $\left({ }^{26} \mathrm{Mg} /{ }^{24} \mathrm{Mg}\right)_{c}=\left({ }^{26} \mathrm{Mg} /{ }^{24} \mathrm{Mg}\right)_{\text {meas }} / \alpha^{2}$, where 'meas' is the measured ratio during the set, $\alpha=\left({ }^{25} \mathrm{Mg} /{ }^{24} \mathrm{Mg}\right)_{\text {meas }} /\left({ }^{25} \mathrm{Mg} /{ }^{24} \mathrm{Mg}\right)_{c}$, and $\left({ }^{25} \mathrm{Mg} /{ }^{24} \mathrm{Mg}\right)_{\mathrm{c}}=0.12663$ reported by Catanzaro et al. (1966).

zolite olivine, and from the Peace River meteorite (L6) were analyzed regularly during these experiments (Table 1 and Fig. 2). The raw measured ratios of ${ }^{25} \mathrm{Mg} /{ }^{24} \mathrm{Mg}$ and ${ }^{26} \mathrm{Mg} /{ }^{24} \mathrm{Mg}$ for 19 separated runs are $0.12464 \pm 0.00017(2 \sigma)$ and $0.13544 \pm 0.00036(2 \sigma)$, respectively. As shown in Fig. 2, the variation of raw measured isotopic ratios of these reference samples were within \pm 2 per mil for ${ }^{25} \mathrm{Mg} /{ }^{24} \mathrm{Mg}$ and \pm 4 per mil for ${ }^{26} \mathrm{Mg} /{ }^{24} \mathrm{Mg}$, indicating that the instrumental mass fractionation was \pm 2 per mil per amu. From the fractionation corrected ${ }^{26} \mathrm{Mg} /{ }^{24} \mathrm{Mg}$ ratios of all normals (19 separate runs) we get the grand mean value of $0.139813 \pm 0.000021(2 \sigma$ mean). For each run we calculated
$\Delta\left({ }^{25} \mathrm{Mg} /{ }^{24} \mathrm{Mg}\right)$ and $\delta^{26} \mathrm{Mg}$ using the following equations:

$$
\begin{aligned}
& \Delta\left({ }^{25} \mathrm{Mg} /{ }^{24} \mathrm{Mg}\right) \\
& \quad=\left[\left({ }^{25} \mathrm{Mg} /{ }^{24} \mathrm{Mg}\right)_{\mathrm{m}} /\left({ }^{25} \mathrm{Mg} /{ }^{24} \mathrm{Mg}\right)_{\mathrm{s}}-1\right] \times 1000
\end{aligned}
$$

and

$$
\delta^{26} \mathrm{Mg}=\left[\left({ }^{26} \mathrm{Mg} /{ }^{24} \mathrm{Mg}\right)_{\mathrm{c}} / 0.139813-1\right] \times 1000,
$$

where ' $\mathrm{m}$ ' is the measured ${ }^{25} \mathrm{Mg} /{ }^{24} \mathrm{Mg}$, ' $\mathrm{s}$ ' is the grand mean value: ${ }^{25} \mathrm{Mg} /{ }^{24} \mathrm{Mg}=0.12464$ for raw data determined from standards, and ' $c$ ' is the fractionation corrected ratio. We can thus resolve differences in ${ }^{26} \mathrm{Mg} /{ }^{24} \mathrm{Mg}$ of $\delta^{26} \mathrm{Mg}= \pm 0.5$ per mil. 


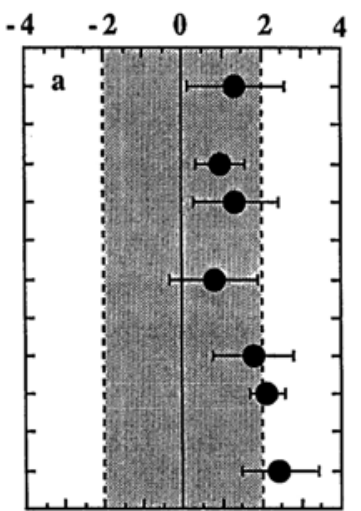

$(0.12464)$

$$
\Delta\left({ }^{25} \mathrm{Mg} /{ }^{24} \mathrm{Mg}\right) \%
$$

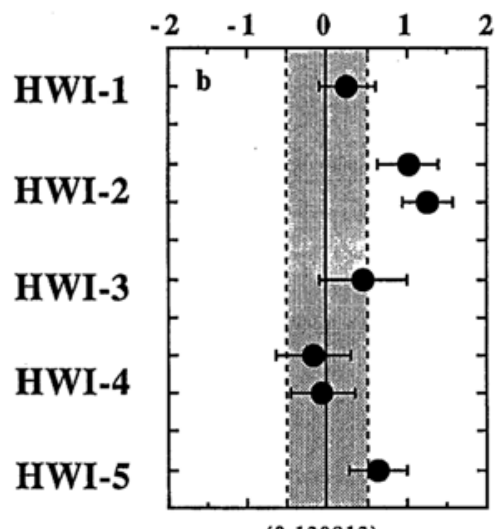

(0.139813)

$\delta^{26} \mathrm{Mg} \%$

Fig. 3. Mg isotopic compositions of 5 stony spherules from deep-sea sediments. (a) Mass fractionation effects of $\mathrm{Mg}$ for the spherules are within a \pm 2 per mil per amu instrumental resolution band. $\Delta\left({ }^{25} \mathrm{Mg} /{ }^{24} \mathrm{Mg}\right)$ $=\left[\left({ }^{25} \mathrm{Mg} /{ }^{24} \mathrm{Mg}\right)_{\mathrm{m}} /\left({ }^{25} \mathrm{Mg} /{ }^{24} \mathrm{Mg}\right)_{s}-1\right] \times 1000$, where ' $\mathrm{m}$ ' is the measured raw ${ }^{25} \mathrm{Mg} /{ }^{24} \mathrm{Mg}$ ratios during the set, ' $s$ ' is the grand mean value: ${ }^{25} \mathrm{Mg} /{ }^{24} \mathrm{Mg}=0.12464$ for raw data determined from standards. (b) Spherule HWI-2 shows a small but significant non-linear effect outside of a \pm 0.5 per mil resolution band. $\delta^{26} \mathrm{Mg}=$ $\left[\left({ }^{26} \mathrm{Mg} /{ }^{24} \mathrm{Mg}\right)_{\mathrm{c}} / 0.139813-1\right] \times 1000$, where ' $c$ ' is the value corrected for fractionation according to $\left({ }^{26} \mathrm{Mg} /{ }^{24} \mathrm{Mg}\right)_{c}=\left({ }^{26} \mathrm{Mg} /{ }^{24} \mathrm{Mg}\right)_{\text {meas }} / \alpha^{2}$, where $\alpha=\left({ }^{25} \mathrm{Mg} /{ }^{24} \mathrm{Mg}\right)_{\text {meas }} /\left({ }^{25} \mathrm{Mg} /{ }^{24} \mathrm{Mg}\right)_{c}$, and $\left({ }^{25} \mathrm{Mg} /{ }^{24} \mathrm{Mg}\right)_{\mathrm{c}}=0.12663$ reported by Catanzaro et al. (1966), and 0.139813 is the grand mean value for all standards normalized using $a$ power law. Errors are $2 \sigma$ for $\Delta\left({ }^{25} \mathrm{Mg} /{ }^{24} \mathrm{Mg}\right)$ or $2 \sigma$ mean for $\delta^{26} \mathrm{Mg}$.

\section{Mass fractionation}

The $\mathrm{Mg}$ isotopic data for the spherules are summarized in Table 1 and shown in Fig. 3. The \pm 2 per mil band in a $\Delta\left({ }^{25} \mathrm{Mg} /{ }^{24} \mathrm{Mg}\right)$ diagram represents the limits of variation for raw ${ }^{25} \mathrm{Mg} /{ }^{24} \mathrm{Mg}$ ratios for standards. Ratios outside of this limit are attributed to intrinsic mass fractionation rather than an artifact during the measurements. Mass fractionations of $\mathrm{Mg}$ for three spherules (HWI-1, -2, and -3) range from 0.8 to 1.4 per mil per amu and are within the range of instrumental mass fractionation. The other two spherules, HWI-4 and -5, show larger mass fractionations of 1.8 to 2.5 per mil per amu. However, they are marginal and indistinguishable within errors from the instrumental mass fractionation.

One can expect a large mass loss of spherules from parent meteoroids due to vaporization during melting events. Based on elemental abundances of one of the glassy spherules analyzed by INAA, Nagasawa et al. (1979) suggested that more than $80 \%$ of the original weight of the parent materials was lost during melting when meteoroids entered the Earth's atmosphere. Recent laboratory distillation experiments (Esat et al., 1986; Esat and Ringwood, 1990; Misawa and Tsuchiyama, 1990; Davis et al., 1990) revealed that $\mathrm{Mg}$ mass fractionation of 2 to 30 per mil per amu was produced when mass loss of 20 to $85 \%$ occurred. If spherules represent vaporization residues of their parent meteoroids, the mass loss of spherules from parent materials by vaporization during entry into the atmosphere is considered to be less than $\sim 20 \%$ by analogy to results from the distillation experiments. Davis et al. (1991) also analyzed $\mathrm{Mg}$ isotopes of 7-250 $\mu \mathrm{m}$ silicate spherules using an ion microprobe, and found that there is little mass fractionation of $\mathrm{Mg}$ in the spherules.

On the other hand, as pointed out by Davis et al. (1991), diffusion coefficients of divalent cations in molten silicate melt considered to be small enough to prevent complete $\mathrm{Mg}$ isotopic equilibration during relatively short periods of heating. Recent numerical calculations for the at- 
mospheric entry of micrometeoroids showed that the peak temperatures experienced these materials usually less than $1700^{\circ} \mathrm{C}$, and that micrometeoroids spend $\sim 2 \mathrm{sec}$ at above liquidus temperatures (Love and Brownlee, 1991). The diffusion coefficients of divalent cations in basalt melt range from $10^{-7}$ to $10^{-6} \mathrm{~cm}^{2} \mathrm{~s}^{-1}$ between 1260 and $1440^{\circ} \mathrm{C}$ at $1 \mathrm{~atm}$ (Hofmann and Magaritz, 1977). Since the diffusion coefficient of $\mathrm{Mg}$ may not be so much different from that of $\mathrm{Ca}$, we can estimate the diffusion coefficient of the order of $10^{-6}$ to $10^{-5} \mathrm{~cm}^{2} \mathrm{~s}^{-1}$ for $\mathrm{Mg}$ based on the extrapolated values from Hofmann and Magaritz's experimental data for $\mathrm{Ca}$ at the temperature range from 1400 to $1700^{\circ} \mathrm{C}$. If high temperature melting of parent meteoroids occurred on the timescale of $\sim 1 \mathrm{sec}$ (Love and Brownlee, 1991), the transport distance of mass fractionated $\mathrm{Mg}$ is less than $30 \mu \mathrm{m}$ even though they totally melted. In this case mass fractionations due to distillation were limited in the outer shell of the molten droplet, therefore, an effective ablative mass loss from parent material may be remained the $\mathrm{Mg}$ isotopic compositions of the inner portion undisturbed. Such an occurrence may be consistent with the observed $\mathrm{Mg}$ isotopic compositions for the spherules.

\section{Non-linear effect}

One sample, HWI-2, shows a small but significant (out of the limit of resolution) nonlinear effect. Repeated analyses suggest that the deviation in this spherule from the normal is real $(+1.02 \pm 0.37$ per mil; $+1.27 \pm 0.31$ per mil), however, it is impossible to determine which isotope is enriched or depleted. We first assumed ${ }^{25} \mathrm{Mg} /{ }^{24} \mathrm{Mg}$ is normal. Of course, the non-linear effect observed here is not due to any chemical fractionations in the deep-sea environment.

$\mathrm{Mg}$ isotopic anomalies have been recognized in several meteoritic constituents. Al-correlated ${ }^{26} \mathrm{Mg}$ excess in $\mathrm{Ca}, \mathrm{Al}$-rich inclusions (CAIs) in carbonaceous chondrites (e.g., Lee et al., 1977 b) and in an igneous clast from the Semarkona LL3.0 chondrite (Hutcheon and Hutchison, 1988) are considered to be due to in situ decay of now extinct ${ }^{26} \mathrm{Al}$ (half-life $\mathrm{T}_{1 / 2}=0.72 \mathrm{Ma}$ ).
Recently, ion microprobe analyses also demonstrated that interstellar grains preserved in chondritic meteorites, especially the CM clan, often show $\mathrm{Mg}$ isotopic anomalies derived from pre-solar ${ }^{26} \mathrm{Al}$ (Zinner et al., 1991). If precursors of the spherules were primitive early solar system material, and the ${ }^{26} \mathrm{Mg}$ excess in HWI-2 is due to in situ decay of ${ }^{26} \mathrm{Al}$, we can estimate an initial ${ }^{26} \mathrm{Al} /{ }^{27} \mathrm{Al}$ ratio using the following equation:

$$
\begin{aligned}
\left({ }^{26} \mathrm{Mg} /{ }^{24} \mathrm{Mg}\right)_{\mathrm{p}}= & \left({ }^{26} \mathrm{Mg} /{ }^{24} \mathrm{Mg}\right)_{0}+\left({ }^{26} \mathrm{Al} /{ }^{27} \mathrm{Al}\right)_{0} \\
& \times\left({ }^{27} \mathrm{Al} /{ }^{24} \mathrm{Mg}\right)_{\mathrm{p}},
\end{aligned}
$$

where ' $p$ ' is the isotopic abundance in the phase or system, and ' 0 ' is the isotopic ratios at the time of homogenization. Assuming $\left({ }^{26} \mathrm{Mg} /{ }^{24} \mathrm{Mg}\right)_{0}$ in the system is normal, and using low $\left({ }^{27} \mathrm{Al} /{ }^{24} \mathrm{Mg}\right)_{\mathrm{p}}$ values of 0.1 to 0.35 from chemical compositions of spherules (Misawa et al., 1992), we obtained $\left({ }^{26} \mathrm{Al} /{ }^{27} \mathrm{Al}\right)_{0}$ values of $1.5 \times 10^{-3}$ to $5 \times 10^{-4}$. They are 10 to 30 times larger than an upper limit of $\sim 5 \times 10^{-5}$ reported for many CAIs in carbonaceous chondrites (e.g., Lee et al., 1977 b). Moreover, there are plenty of differences in their chemical and petrological characteristics between CAIs and stony spherules. CAIs possessing ${ }^{26} \mathrm{Mg}$ excesses mainly consist of high temperature minerals such as AlTi-rich pyroxene, anorthite, melilite, and spinel, which are very different from constituents of stony spherules. Major and trace element abundances for stony spherules are chondritic even if they melted during the atmospheric entry, but elemental abundances for CAIs are enriched in both refractory lithophile and siderophile elements. We thus believe this is not the case.

The effects of substantial interactions with nuclear active particles are second possibilities for the $\mathrm{Mg}$ isotopic anomalies. A subset of IDPs, chondritic aggregates, exhibits similar but larger anomalies in $\mathrm{Mg}$. Esat et al. (1979) and Esat and Taylor (1987) measured 18 IDPs and found 6 particles that show statistically significant excesses in ${ }^{26} \mathrm{Mg} /{ }^{24} \mathrm{Mg}$ ranging from 3 to 4 per mil. Esat (1988) suggested that these anomalies could be related to physicochemical effects such as sputtering of the solar wind and solar flare particles. The application of this 
mechanism cannot totally explain the $\mathrm{Mg}$ isotopic effect observed in the stony spherule, since the mass of the spherules analyzed in this study is 3 to 4 orders of magnitude larger than that of IDPs. If the parent meteoroids of stony spherules were small ( $\sim 10-100 \mu \mathrm{g}$ in weight) and irradiated for $10^{5}-10^{7}$ years in interplanetary space (Raisbeck et al., 1983; Nishiizumi et al., 1991), sputtering by galactic cosmic rays and solar cosmic rays may have occurred only at the surface of the meteoroids.

Isotopic anomalies induced by the distillation-condensation processes are another possibilities for the non-linear isotopic effects. Esat et al. (1986) and Misawa and Tsuchiyama (1990) reported on non-linear $\mathrm{Mg}$ isotopic effects ( $\delta^{26} \mathrm{Mg}$ ranges from +1 to +2.3 per mil) for silicates condensed from gas phases. Since these condensates show large mass fractionations highly enriched in the light isotope, ${ }^{24} \mathrm{Mg}$, this mechanism appears to be incompatible with the normal ${ }^{25} \mathrm{Mg} /{ }^{24} \mathrm{Mg}$ data for spherules.

The origin of the non-linear effect on $\mathrm{Mg}$ isotopes observed in HWI-2 remains obscure. Therefore, a more complicated mechanism should be considered.

\section{Conclusions}

We analyzed the $\mathrm{Mg}$ isotopes of 5 individual stony spherules collected from deep-sea sediments. All spherules show normal ${ }^{25} \mathrm{Mg} /{ }^{24} \mathrm{Mg}$ ratios within the range of instrumental mass fractionation ( 2 per mil per amu), suggesting that either mass loss from parent meteoroids of spherules by vaporization was not so large, or ablative mass loss from parent meteoroids occurred effectively during entry into the Earth's atmosphere. One spherule shows a small but significant non-linear effect of ${ }^{26} \mathrm{Mg}\left(\delta^{26} \mathrm{Mg}=+1.2\right.$ per mil $)$ similar to those observed in IDPs. Since physicochemical fractionation effects in interplanetary space may be responsible for the observed $\mathrm{Mg}$ isotopic effect, further laboratory distillation and sputtering experiments as well as detailed studies on chemical and isotopic compositions for primitive meteorites, IDPs, and micrometeorites are required.

Acknowledgments-Silica gel and phosphoric acid used in this work were kindly supplied by $T$. Shimamura and Y. Hirao. We are indebted to N. Fujii for use of the SEM-EDS at Kobe University, and to E. Takahashi for providing us with some KLB-1 lherzolite through N. Fujii. One of the authors (K. M.) is grateful to T. Shimaoka for assistance with the SEM work. We would like to thank W. R. Premo for improving English. This work was supported in part from the cooperative program provided by the Institute for Cosmic Ray Research, University of Tokyo and by a Grant-in-Aid for Encouragement of Young Scientists of the Ministry of Education, Science and Culture, Japan.

\section{REFERENCES}

Brownlee, D. E. (1981) Extraterrestrial components. The Sea., Vol. 7, Emiliani, C. ed., pp. 733-762, Wiley, New York.

Brownlee, D. E. (1985) Cosmic dust: Collection and research. Ann. Rev. Earth Planet. Sci. 13, 147-173.

Catanzaro, E. J., Murphy, T. J., Gamer, E. L. and Shield, W. R. (1966) Absolute isotopic abundance ratios and atomic weight of magnesium. J. Res. N.B.S. 70A, 453-458.

Clayton, R. N., Mayeda, T. K. and Brownlee, D. E. (1986) Oxygen isotopes in deep-sea spherules. Earth Planet. Sci. Lett. 79, 235-240.

Davis, A. M., Clayton, R. N., Mayeda, T. K. and Brownlee, D. E. (1991) Large mass fractionation of iron isotopes in cosmic spherules collected from deep-sea sediments (abstract). Lunar Planet. Sci. XXII, 281-282.

Davis, A. M., Hashimoto, A., Clayton, R. N. and Mayeda, T. K. (1990) Isotope mass fractionation during evaporation of $\mathrm{Mg}_{2} \mathrm{SiO}_{4}$. Nature 347, 655658.

Esat, T. M. (1988) Physicochemical isotope anomalies. Geochim. Cosmochim. Acta 52, 1409-1424.

Esat, T. M., Brownlee, D. E., Papanastassiou, D. A. and Wasserburg, G. J. (1979) Magnesium isotopic composition of interplanetary dust particles. Science 206, 190-197.

Esat, T. M. and Ringwood, A. E. (1990) Constraints placed on bulk moon composition from $\mathrm{Mg}$ isotope fractionation in vaporized pyrolite (abstract). Lunar Planet. Sci. XXI, 329-330.

Esat, T. M., Spear, R. H. and Taylor, S. R. (1986) Isotope anomalies induced in laboratory distillation. Nature 319, 576-578. 
Esat, T. M. and Taylor, S. R. (1987) Mg isotopic composition of some interplanetary dust particles (abstract). Lunar Planet. Sci. XVIII, 269-270.

Hofmann, A. W. and Magaritz, M. (1977) Diffusion of $\mathrm{Ca}, \mathrm{Sr}, \mathrm{Ba}$, and $\mathrm{Co}$ in a basalt melt: implications for the geochemistry of the mantle. J. Geophys. Res. 82, 5432-5440.

Hutcheon, I. D. and Hutchison, R. (1988) Evidence of the in situ decay of ${ }^{26} \mathrm{Al}$ in the Semarkona ordinary chondrite. Nature 337, 238-241.

Lee, T., Papanastassiou, D. A. and Wasserburg, G. J. (1977 a) $\mathrm{Mg}$ and $\mathrm{Ca}$ isotopic study of individual microscopic crystals from the Allende meteorite by the direct loading technique. Geochim. Cosmochim. Acta 41, 1473-1485.

Lee, T., Papanastassiou, D. A. and Wasserburg, G. J. $(1977 \mathrm{~b}){ }^{26} \mathrm{Al}$ in the early solar system: fossil or fuel ? Astrophys. J. 211, L107-L110.

Love, S. G. and Brownlee, D. E. (1991) Heating and thermal transformation of micrometeoroids entering the Earth's atmosphere. Icarus 89, 26-43.

Misawa, K. and Nakamura, N. (1988) Demonstration of REE fractionation among individual chondrules from the Allende (CV3) chondrite. Geochim. Cosmochim. Acta 52, 1699-1710.

Misawa, K. and Tsuchiyama, A. (1990) Mg isotopic composition of silicates produced from gas-condensation furnace (abstract). Sym. Antarctic Meteorites 15, 170.

Misawa, K. and Yamakoshi, K. (1990) Mg isotopic composition of stony spherules from deep-sea sediments. Oral presentation at IAU Colloquium No. 126. 'Origin and Evolution of Interplanetary Dust', Kyoto, Japan.

Misawa, K., Yamakoshi, K., Nogami, K., Yamamoto, K. and Nakamura, N. (1992) Rare earth element abundances in stony spherules from deep-sea sediments. (submitted to Geochem. J.)

Nagasawa, H., Yamakoshi, K. and Shimamura, T. (1979) Trace element concentration in silicate spherules from ocean sediments. Geochim. Cosmochim. Acta 43, 267-272.

Nishiizumi, K., Arnold, J. R., Fink, D., Klein, J., Middleton, R., Brownlee, D. E. and Maurette, M. (1991) Exposure history of individual cosmic particles. Earth Planet. Sci. Lett. 104, 315-324.

Raisbeck, G. M., Yiou, F., Klein, J., Middleton, R., Yamakoshi, K. and Brownlee, D. E. (1983) ${ }^{26} \mathrm{Al}$ and ${ }^{10} \mathrm{Be}$ in deep sea stony spherules; Evidence for small parent bodies (abstract). Lunar Planet. Sci. XIV, 622-623.

Schramm, D. N., Tera, F. and Wasserburg, G. J. (1970) The isotopic abundance of ${ }^{26} \mathrm{Mg}$ and limits on ${ }^{26} \mathrm{Al}$ in the early solar system. Earth Planet. Sci. Lett. 10, 44-59.

Zinner, N., Amari, S., Anders, E. and Lewis, R. (1991) Large amounts of extinct ${ }^{26} \mathrm{Al}$ in interstellar grains from the Murchison meteorite. Nature 349, 51-54. 